International Journal of Applied Dental Sciences 2021; 7(2): 251-254

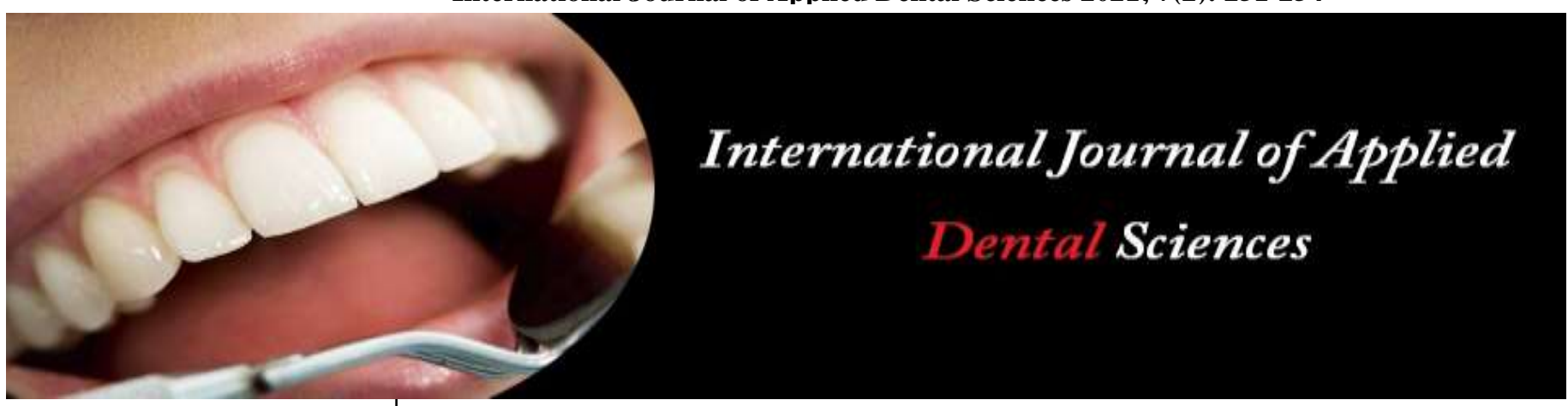

ISSN Print: 2394-7489

ISSN Online: 2394-7497

IJADS 2021; 7(2): 251-254

(C) 2021 IJADS

www.oraljournal.com

Received: 06-02-2021

Accepted: 22-03-2021

Jibin Joy

Post Graduate Student,

Department of Orthodontics, AJ

Institute of Dental sciences,

Mangalore, Karnataka, India

Anilkumar

Reader, Department of

Orthodontics, AJ Institute of

Dental sciences, Mangalore,

Karnataka, India

\section{Methods of maxillary arch expansion in orthodontics: A literature review}

\section{Jibin Joy and Anilkumar}

DOI: $\underline{\text { https://doi.org/10.22271/oral.2021.v7.i2d.1218 }}$

\section{Abstract}

The expansion of the arch has been one of the oldest means of creating space in the dental arches. The correction of transverse maxillary deficiency can be an important component of an orthodontic treatment plan. For the correction of transverse maxillary deficiency, based on the duration of time taken to achieve the desired expansion, expansion devices can be classified as- Rapid maxillary expansion devices and slow expansion devices. This article focuses on the various appliances that can be used for the expansion of maxillary arch.

Keywords: Maxillary arch expansion, rapid maxillary expansion devices, slow maxillary expansion devices

\section{Introduction}

The first reported use of expansion device, dates back to the year 1860, when Emerson C Angell first used a double jackscrew kind of an appliance to expand the maxillary arch in a 14.5 year old girl ${ }^{[1]}$. Correction of the transverse discrepancy usually requires expansion of the palate by a combination of orthopedic and orthodontic tooth movements. Three expansion treatment modalities are used today: rapid maxillary expansion (RME), slow maxillary expansion (SME) and surgically assisted maxillary expansion ${ }^{[2]}$. Normal palatal growth is nearly complete by age $6,{ }^{[3]}$ and increasing interdigitation of the suture makes separation difficult to achieve after puberty ${ }^{[4]}$. If the force is strong enough, separation occurs at the maxillary suture. Expansion appliances can be used for the correction of crossbites, for distal molar movement, along with functional appliance treatment, surgical cases for instance arch coordination or bone grafts, to aid maxillary protraction and mild crowding. This article aims to review the appliances that are used for maxillary arch expansion.

\section{Slow Maxillary Expansion (Sme)}

It uses lighter forces for a longer period of time to expand the maxillary arch. It is primarily planned to produce dentoalveolar expansion or changes. Slow expansion has been found to promote greater post-expansion stability, if given an adequate retention period. It delivers a constant physiologic force until the required expansion is obtained ${ }^{[5]}$. SME produces more stable results when the maxillary arch is expanded slowly at a rate of $0.5-1 \mathrm{~mm} / \mathrm{week}$. The force generated in slow expansion is $2-4$ pounds and takes about 2-5 months ${ }^{[6]}$.

\section{Appliances used for slow expansion}

\section{W-Arch ${ }^{\text {2] }}$}

The "W"; expansion appliance was originally used by Ricketts and his colleagues ${ }^{[7]}$ to treat cleft palate patients. The $\mathrm{W}$-arch is a fixed appliance constructed of 36 mil steel wire soldered to molar bands. To avoid soft tissue irritation, the lingual arch should be constructed so that it rests 1-1.5 mm off the palatal soft tissue. It is activated simply by opening the apices of Warch and is easily adjusted to provide more anterior than posterior expansion, or vice versa if this is desired. The appliance delivers proper force levels when opened 3-4 mm wider than the passive width and should be adjusted to this dimension before being inserted. Expansion should continue at the rate of $2 \mathrm{~mm}$ per month until the cross bite is slightly overcorrected.

\section{Corresponding Author:}

Jibin Joy

Post Graduate Student,

Department of Orthodontics, AJ

Institute of Dental sciences,

Mangalore, Karnataka, India 


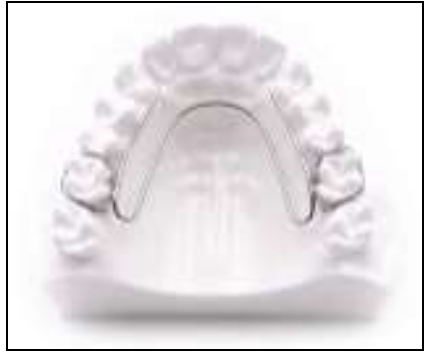

\section{Coffin Appliance ${ }^{[8]}$}

Given by Walter Coffin-1875. It is a removable appliance (fig1) capable of slow dento alveolar expansion. The appliance consists of an omega-shaped wire of $1.25 \mathrm{~mm}$ thickness, placed in the midpalatal region. The free ends of the omega wire are embedded in acrylic covering the slopes of the palate. The spring is activated by pulling two asides apart manually.

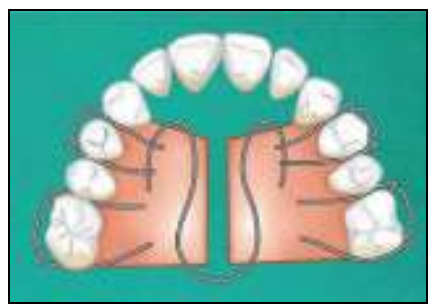

\section{Quadhelix ${ }^{[9]}$}

The quadhelix appliance is a modification of Coffin's Wspring and was described by Ricketts. The incorporation of four helices into the $\mathrm{W}$-spring helped to increase the flexibility and range of activation. The length of the palatal arms of the appliance can be altered depending upon which teeth arch in crossbite. The action of the quad helix appliance is to buccally expand and to distally rotate the maxillary molar teeth and then, because the extended arms have a fanlike sweeping action, they can be adjusted to expand the maxillary bicuspid and cuspid teeth. Studies investigating the force vectors of the quad helix appliance ${ }^{[10]}$ report that the anterior arms of the appliance affect both the forces produced by the appliance as well as the force couples operating on the molar teeth. This results from the fact that the anterior arms are a rigid part of the whole appliance. Other studies ${ }^{11}$ indicated that the quad helix appliance has the ability to derotate the molar teeth more efficiently than the Haas appliance, and that the quad helix appliance can expand differentially anterioposteriorly.

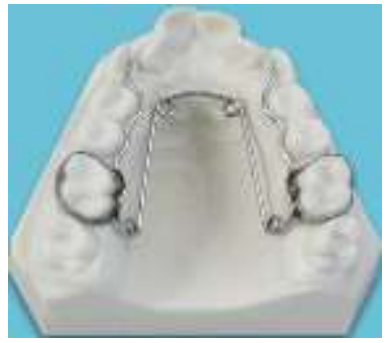

\section{NiTi Expander ${ }^{[11]}$}

The Nickel Titanium Palatal Expanders were introduced by Wendell V ${ }^{[11]}$. It generates optimal, constant expansion forces. The central component is made of a thermally activated NiTi alloy and rest of component is made of stainless steel. The expander may be used simultaneously with conventional fixed appliances, requiring only an additional lingual sheath on the molar bands.
The action of the appliance is a consequence of nickel titanium's shape memory and transition temperature effects. ${ }^{12}$ The nickel titanium component has a transition temperature of $94^{\circ} \mathrm{F}$. At room temperature, the expander is too stiff to bend for insertion. Chilling the expander softens the central component allowing easy manipulation. Once placed, stiffens and begins to return to its original shape. A $3 \mathrm{~mm}$ increment of expansion exerts only about $350 \mathrm{gm}$ of force ${ }^{13}$ and the nickel titanium alloy provides relatively uniform force levels as the expander deactivates.

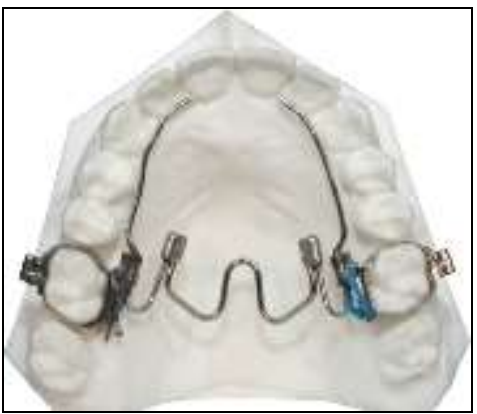

Rapid Palatal Expansion Appliances

RME is a dentofacial orthopedic procedure that involves the separation of midpalatal suture and movement of the maxillary shelves away from each other. It provide skeletal type of expansion. Advocates of rapid maxillary expansion believe that it results in minimum dental movement (tipping) and maximum skeletal movement ${ }^{[14]}$. An increase in maxillary arch width upto $10 \mathrm{~mm}$ can be achieved by RME. The rate of expansion is about $0.2-0.5 \mathrm{~mm}$ per day. When the force delivered by the appliance exceeds the limit needed for orthodontic tooth movement and sutural resistance, the sutures open up while the teeth move only minimally relative to their supporting bone. The appliance compresses the periodontal ligament, bends the alveolar process, tips the anchor teeth, and gradually opens the midpalatal suture and all the other maxillary sutures.

\section{Appliances used for Rapid Maxillary Expansion}

1. 1.Removable appliances

2. Fixed appliance

- Tooth borne

1. Isaacson type

2. Hyrax type

- Tooth and Tissue borne

1. Derichsweiler type

2. Hass type

These are banded and bonded appliances. The banded appliance are attached to teeth with bands on the maxillary first molar and first premolars. The banded appliances are hygienic as there is no palatal coverage. The banded RME are of two types:

\section{Tooth and tissue borne}

Haas: The basis for the rapid expansion procedure is to produce immediate midpalatal suture separation by disruption of the sutural connective tissue.

The rapid palatal expander as described by Haas is a rigid appliance designed for maximum dental anchorage that uses a jackscrew to produce expansion in 10 to 14 days. ${ }^{[15]} \mathrm{He}$ believed that this will maximize the orthopedic effects and 
forces produced by this appliance have been reported in the range of 3 to 10 pounds.

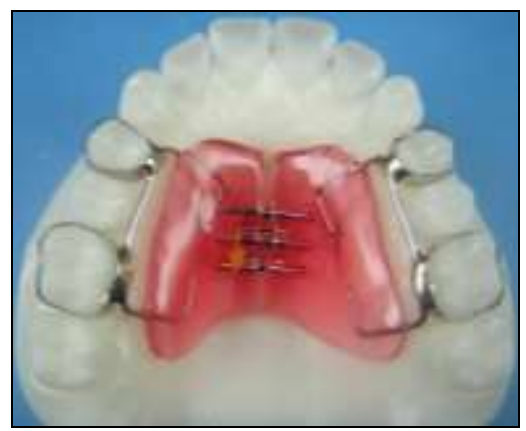

Derichsweiler: The first premolar and molars are banded. Wire tags are soldered to these bands and then inserted to the split palatal acrylic, which contains the screw.

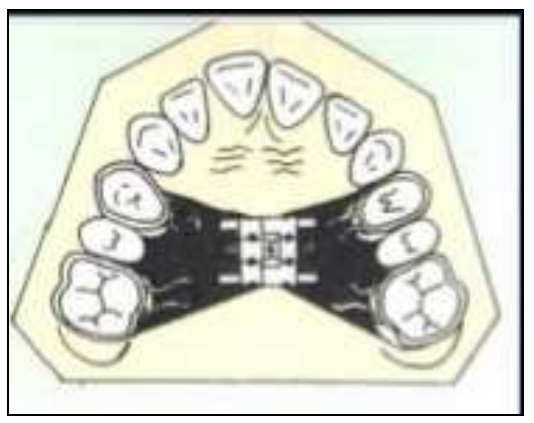

\section{Tooth borne RME}

HYRAX expander: It is a tooth borne appliance, which was introduced by William Biederman in 1968. This type of appliance makes use of a special screw called HYRAX (Hygenic Rapid Expander). The Hyrax Expander is essentially a nonspring loaded jackscrew with an all wire frame. ${ }^{16}$ The screws have heavy gauge wire extensions that are adapted to follow the palatal contours and soldered to bands on premolar and molar.

The main advantage of this expander is that it does not irritate the palatal mucosa and is easy to keep clean. It is capable of providing sutural separation of $11 \mathrm{~mm}$ within a very short period of wear and a maximum of $13 \mathrm{~mm}$ can also be achieved. Each activation of the screw produces approximately $0.2 \mathrm{~mm}$ of lateral expansion and it is activated from front to back.

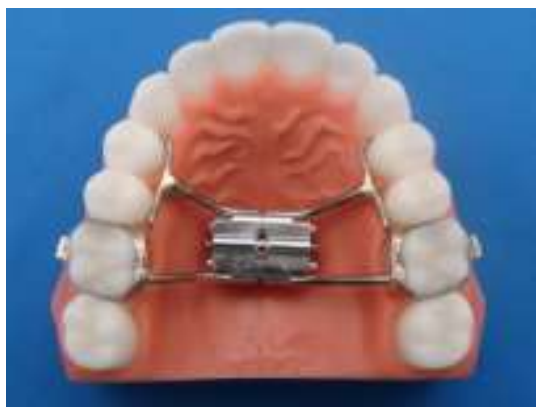

Issacson expander: It is a tooth borne appliance without any palatal covering. This expander makes use of a spring loaded screw called Minne expander (developed by university of Minnesota, dental school), which is soldered directly to the bands on first premolar and molars ${ }^{[17]}$. The Minne expander is a heavily calibrated coil spring expanded by turning a nut to compress the coil. Two metal flanges perpendicular to the coil are soldered to the bands on abutment teeth. The Minne expander may continue to exert expansion forces after completion of the expansion phase unless they are partly deactivated.

\section{Bonded Rapid palatal Expander}

The Bonded RPE were first described by Cohen and Silverman in 1973. It is similar to the banded version with the exception of the method of attachment to the teeth. This appliance is constructed with an acrylic cap over the posterior segments, which is then bonded directly to the teeth ${ }^{[18]}$.

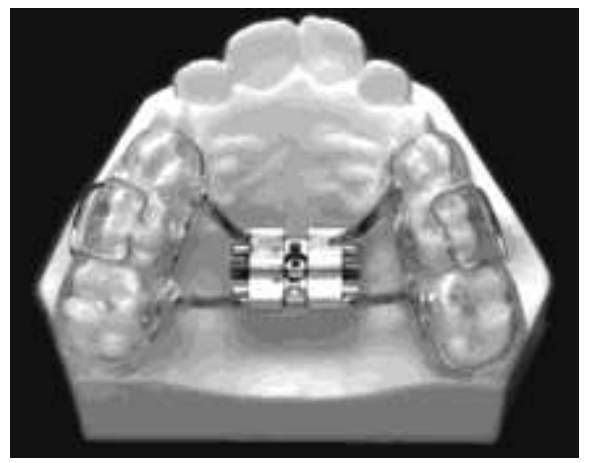

Surgically Assisted Rapid Palatal Expander (Sarpe)

Surgically assisted RPE is an alternative method which reduces resistance of the closed midpalatal suture to correct maxillary constriction in an adult. It helps to achieve effective maxillary expansion in a skeletally mature patients.

The following have been reported in the literature as indications for SARPE, all applying to a skeletally mature patient with a constricted maxillary arch ${ }^{[19,20]}$.

1. To increase maxillary arch perimeter, to correct posterior crossbite, and when no additional surgical jaw movements are planned.

2. To widen the maxillary arch as a preliminary procedure, even if further orthognathic surgery is planned. This is to avoid increased risks, inaccuracy, and instability associated with segmental maxillary osteotomy.

3. To provide space for a crowded maxillary dentition when extractions are not indicated.

4. To widen maxillary hypoplasia associated with clefts of the palate.

5. To reduce wide black buccal corridors when smiling.

6. To overcome the resistance of the sutures when OME has failed.

\section{Amount of expansion}

Betts et al. ${ }^{[21]}$ and others ${ }^{[22]}$ have recommended that the amount of desired expansion is an important factor in case selection for maxillary expansion in adults. In general, an orthodontist can camouflage transverse maxillomandibular discrepancies less than $5 \mathrm{~mm}$ with orthopedic or orthodontic forces alone. When the MTD is greater than $5 \mathrm{~mm}$, surgical assistance is essential. Although both SARPE and segmental osteotomy are used for surgically assisted maxillary expansion, segmental osteotomy is reported to be unstable, especially when more than $8 \mathrm{~mm}$ expansion is desired. ${ }^{23}$ It is also essential to evaluate the buccolingual inclination of the teeth because that may either mask or aggravate the discrepancy at the apical bases.

\section{Complication}

Palatal tissue irritation is a frequent complication of SARPE. Irritation occurs due to impingement of appliance or rapid rate of expansion [24] 
Other complications include haemorrhage, gingival recession, root resorption, sinus infection, extrusion of teeth, relapse and unilateral expansion ${ }^{[25]}$.

\section{Micro Implant Assisted R.M.E}

To achieve maximum skeletal expansion by overcoming the undesirable dento-alveolar effects, a non-surgical MICROIMPLANT-assisted R.M.E technique was introduced [26].

Miniscrews are employed onto the maxillary expanders that recruits palatal and nasal cortices which provides anchorage that facilitates opening of midpalatal suture and helps to overcome resistance from circum maxillary sutures.

Paramedian area $3 \mathrm{~mm}$ lateral to the suture in 1st premolar region is considered the most appropriate site for placement of miniscrews, anterior screws are placed in rugae ${ }^{[27]}$

As the appliance is tooth and tissue borne, it is used in late teens to mid-twenties. clinical observations suggest that MARPE prevents many adverse effects of RPE and is preferred as effective alternative for the same.

\section{Conclusion}

Expansion of the maxilla and the maxillary dentition may be accomplished in numerous ways. The type of skeletal and dental pattern greatly influences the type of expansion chosen and the type of expansion selected can greatly facilitate the overall treatment objectives. The maturity of the maxillafacial structures determines the time and success rate of the treatment with RME.

\section{References}

1. Emerson Angell C. (1822-1903). Founding father of rapid maxillary expansion D J Timms. Dent Hist 1997;(32):3-12.

2. Agarwal A, Mathur R. Maxillary expansion. International journal of clinical pediatric dentistry 2010;3(3):139.

3. Moyers RE, van der Linden FP, Riolo ML. Standards of human occlusal development. In: Monograph 5, craniofacial growth series, Center for Human Growth and Development, 7 th ed. University of Michigan: Ann Arbor 1976.

4. Persson M, Thilander B. Palatal suture closure in man from 15 to 35 years of age. Am J Orthod 1977;72(1):4252.

5. Cleall JF, Bayne DI, Posen JM, Subtelny JD. Expansion of the midpalatal suture in the monkey. The Angle Orthodontist 1965;35(1):23-35.

6. Hicks EP. Slow maxillary expansion. A clinical study of the skeletal versus dental response to low-magnitude force. Am J Orthod 1978;73(2):121-141.

7. Ricketts RM, Bench RW, Gungino CF. Bio progressive therapy. Rocky Mountain/ Orthodontics 1979, 255-258.

8. The origin of treatment expansion. Philippe J. Am J Orthod Dentofacial Orthop 2007;131(4):446.

9. Bench RW. The quad helix appliance. Seminars in Orthodontics 1998;4(4):231-237.

10. Jones SP, Waters NE. The quad helix maxillary expansion appliance: Part 1. Eur J Orthod 1989, 169-178.

11. Ladner PT, Muhl ZE. Changes concurrent with orthodontic treatment when maxillary expansion is a primary goal. Am J Orthod Dentofac Orthop 1995;108:184-193.

12. Arndt WV. Nickel titanium palatal expander. J Clin Orthod 1993;27(3):129-137.

13. Marzban R, Nanda R. Slow maxillary expansion with nickel titanium. J Clin Orthod. 1999;33(8):431-441.

14. Bell RA. A review of maxillary expansion in relation to rate of expansion and patient's age. Am J Orthod. 1982;81(1):32-37.

15. Haas AJ. The treatment of maxillary deficiency by opening the midpalatal suture. Angle Orthod. 1965;35:200-217.

16. Bishara SE, Staley RN. Maxillary expansion: clinical implications. Am J Orthod Dentofacial Orthop 1987;91(1):3-14.

17. Bishara SE, Staley RN. Maxillary expansion: Clinical implication. Am J Orthod Dentofacial Orthop 1987;91(1):3-14.

18. Sarver DM, Johnston MW. Skeletal changes in vertical anterior displacement of maxilla with bonded rapid palatal expander appliances. Am J Orthod Dentofacial Orthop 1989;95(6):462-466.

19. Woods M, Wiesenfeld D, Probert T. Surgically-assisted maxillary expansion. Aust Dent J 1997;42:38-42.

20. Koudstaal MJ, Poort LJ, van der Wal KG, Wolvius EB, Prahl-Andersen B, Schulten AJ. Surgically assisted rapid maxillary expansion (SARME): a review of the literature. Int J Oral Maxillofac Surg 2005;34:709-14.

21. Betts NJ, Vanarsdall RL, Barber HD, Higgins-Barber K, Fonseca RJ. Diagnosis and treatment of transverse maxillary deficiency. Int J Adult Orthod Orthognath Surg 1995;10:75-96.

22. Silverstein K, Quinn PD. Surgically-assisted rapid palatal expansion for management of transverse maxillary deficiency. J Oral Maxillofac Surg 1997;55:725-7.

23. Woods M, Wiesenfeld D, Probert T. Surgically-assisted maxillary expansion. Aust Dent J 1997;42:38-42.

24. Carmen M, Marcella P, Giuseppe C, Roberto A. Periodontal evaluation in patients undergoing maxillary expansion. Journal of Craniofacial Surgery. 2000;11(5):491-4. 6.

25. Vardimon AD, Graber TM, Pitaru S. Repair process of external root resorption subsequent to palatal expansion treatment. American Journal of Orthodontics and Dentofacial Orthopedics 1993;103(2):120- 30.

26. Lee KJ, Park YC, Park JY, Hwang WS. Miniscrewassisted nonsurgical palatal expansion before orthognathic surgery for a patient with severe mandibular prognathism. American Journal of Orthodontics and Dentofacial Orthopedics 2010;137(6):830-9.

27. Moon SH, Park SH, Lim WH, Chun YS. Palatal bone density in adult subjects: implications for miniimplant placement. The Angle Orthodontist 2010;80(1):137-44. 